\title{
MOVEMENTS OF FLORAL PARTS AND ROLES OF THE TOOTH ON THE COLUMN WALL OF BULBOPHYLLUM PRAETERVISUM (ORCHIDACEAE) FLOWER IN POLLINATION BY DACINI FRUIT FLIES (DIPTERA: TEPHRITIDAE)
}

\author{
Tan, Keng Hong*1,2 and Tan, Lin Tze ${ }^{3}$ \\ ${ }^{l}$ Mobula Research Sdn. Bhd., 20, Jalan Tan Jit Seng, 11200 Penang, Malaysia \\ ${ }^{2}$ Academy of Sciences Malaysia, MATRADE Tower, Jalan Sultan Haji Ahmad Shah, 50480 Kuala Lumpur, Malaysia \\ ${ }^{3}$ Bachemer Strasse, 20, Bonn, 53179 Germany
}

\begin{abstract}
Bulbophyllum is the largest genus of the orchid family, with about 2000 species that are mainly pollinated by flies. Flowers of many Bulbophyllum species under the Sections Sestochilos and Beccariana specifically attract Dacini fruit flies, Bactrocera and Zeugodacus species, as pollinators. Non-nectar producing and non-resupinate solitary flowers of Bu. pratervisum emit specific and pleasant floral fragrances to specifically attract and reward male fruit flies. Slippery surfaces on their lateral sepals aid in pollination. Although pollinia removal by male fruit flies has been observed frequently, deposition of pollinia to complete pollination (by two males of Ba. albistrigata and $Z$. caudatus) has only been observed recently. Field observations show two previously unreported movements of floral parts - a) petals and medial sepal during daily closing and reopening of flowers, and b) the spring-loaded and hinged lip during removal and deposition of pollinia by a male fruit fly. Additionally, a third (novel) movement has been observed, either when the flower closes for the night to protect the stigma, or after a fly has deposited the pollinia onto the stigma, the 'acute tooth' on each column wall folds inwards specifically to secure the newly deposited pollinia.
\end{abstract}

Keywords: Daciniphilous orchid, Bulbophyllum praetervisum, floral parts, movements, pollination, pollinators, Dacini fruit flies.

\section{INTRODUCTION}

Orchids have fascinating pollination mechanisms (Baker, H.G. I963, Jersakova et al. 2006, Lord \& Russell 2002, Tan \& Nishida 2013), frequently including display (via bright colour) and deception (via fragrance/odour). The odour deception can take four different forms: a) food: b) a female mate to stimulate pseudo-copulation of a potential pollinator (Schiestl et al. 2003): c) a carcass/wound to attract carrion and flesh flies belonging to Calliphoridae and Sarcophagidae, respectively, (Ong \& Tan 20II): or d) dung or/and rotting vegetation to attract black scavenger flies, Dicranosepsis species (Sepsidae) (first case for this family- manuscript in preparation) as pollinators.

Bulbophyllum, with approximately 2000 recognized species, is the largest genus of Orchidaceae. The flowers possess a highly mobile and functional hinged lip and are well known for releasing a fetid/unpleasant odour (Pijl \& Dobson 1969; Kaiser 1993; Cingel 200I). They are mainly pollinated by flies from various families -6 under suborder Nematocera

Received 3 May 2018, accepted 17 October 2018

${ }^{*}$ Corresponding author: tan.kenghong@yahoo.com
- Cecidomyiidae, Chironomidae, Culicidae, Mycetophilidae, Psychodidae, Sciaridae; and II under suborder Brachycera Anthomyzidae, Calliphoridae, Drosophilidae, Empididae, Ephydridae, Fanniidae, Lonchaeidae, Milichiidae, Muscidae, Phoridae, Sarcophagidae, Tachinidae, and Tephritidae (Christensen 1994; Larson et al. 200I; Woodcock et al. 2014 - and references therein). Recent additions of dipteran families from the suborder Brachycera are Platystomatidae (Ong \& Tan 20II) and Sepsidae (unpublished data manuscript in preparation). Some other dipteran families are known as just floral visitors, e.g. Bibionidae (Nematocera), and several under the suborder Brachycera, e.g. Bombyliidae, Conopidae, Nemestrinidae, Stratiomyidae, and Syrphidae (Kastinger \& Weber 200I; Larson et al. 200I) and Sepsidae (Flügel 2013).

Many Bulbophyllum species under the Section Sestochilos (Breda) Benth. \& Hook.f., and Beccariana Pfitz. attract carrion (Calliphoridae), flesh (Sarcophagidae), and signal (Platystomatidae) flies via deception, using fetid/carrion odour for pollination - (Ong \& Tan 20II). Intriguingly, under the same Sections, there are also many daciniphilous species of Bulbophyllum. These produce neither nectar nor fetid odour, and attract males of tribe Dacini, mainly Bactrocera and Zeugodacus species (Tephritidae: Diptera). These daciniphilous orchids specifically release pleasant spicy 
or fragrant odours that are pleasant to humans. Fascinatingly, these attractants also act as floral rewards - e.g. (i) methyl eugenol (ME) to attract certain ME-responsive species (Nishida et al. 2004; Tan \& Nishida 20I2; Tan et al. 2002, 2006), ii) raspberry ketone (RK) for RK-responsive species (Tan \& Nishida 2005), and iii) zingerone for both ME- and RK-responsive species (Tan \& Nishida 2000, 2007) exclusively for many fruit fly species, belonging to the two Dacini genera - Bactrocera and Zeugodacus (combined $>500$ species), as pollinators and/or visitors.

Flowers of most Bulbophyllum species possess a highly modified and movable lip (labellum) to assist in crosspollination (Vermeulen 199I; Chan et al. I994; Tan 2009, Tan and Nishida 2013). Ridley (I890) reported that of Bu. macranthum Lindl. was pollinated and fertilised by a 'small fly' (probably either a Bactrocera or Zeugodacus species). Later, this species was reported to be pollinated by tephritid fruit flies - namely Ba. albistrigata (Radian \& Padmarsari 20I2), although the actual deposition of pollinia onto the stigma was not observed. A similar pollination mechanism was observed in a closely related sibling species, Bu. praetervisum J.J. Verm. Flowers of Bu. praetervisum release mainly RK while those of $\mathrm{Bu}$. macranthum release zingerone (except a chemotype from Philippines) to attract males of certain Bactrocera and Zeugodacus species for pollination (Nakahira et al. 2018). The floral $\mathrm{RK}$ also entices and rewards the attracted flies as vectors for pollination. In this mutualistic inter-relationship, both the orchid and the fruit fly gain sexual reproductive benefits (Tan and Nishida 2005). Flowers of Bu. praetervisum differ from those of $\mathrm{Bu}$. macranthum by having "a triangular and acute tooth along the lower margin of each stelidium" (Vermeulen, 2002). Since there is no published report on either the movements of floral parts or the role of the floral tooth on each column lateral wall (CLW), we describe and discuss a) three movements shown by different sets of floral parts to ensure successful pollination from blooming until just before fertilisation, and b) the roles of the tooth on each CLW in Bu. praetervisum flowers.

\section{MATERIALS AND METHODS}

\section{Plant materials}

Original plants, purchased in early 1990s from Kundasang, Sabah, East Malaysia, and as gifts from J.J. Vermeulen, were labelled and each grown on a section of either a tree branch or fern stem ex situ in Penang.

Estimation of torsional force of the hinged and spring-loaded lip

A solitary fresh flower was plucked, and the petals and sepals were carefully removed without ever touching the very delicate hinged and spring-loaded lip. This precaution required because the lip could be easily detached from the hinge even by the slightest lateral force. The flower was carefully and firmly attached to a movable platform using a narrow strip of parafilm. The tip of the lip, still in a naturally open position, was carefully adjusted to sit on a modified weighing pan of a torsion balance $(0-50 \mathrm{mg}$ with sensitivity of $0.1 \mathrm{mg}$ ). The torsional force of the spring-loaded lip was then estimated by measuring the weight required to lift the lip from an open to a closed position. An average of at least five weighings was obtained for each flower. This procedure was repeated for four flowers within 3 hours after anthesis.

Artificial pollination to show movement of column lateral wall (CLW) and its acute tooth

Deposition of pollinia by a male Dacini fruit fly is not commonly observed; and it has only been witnessed twice in the last two decades. Therefore, it was necessary to perform artificial pollination to study movements of CLW and its acute tooth to confirm our observation after the witnessing the two natural depositions of pollinia. Pollinia from a $\mathrm{Bu}$. pratervisum flower were removed using the head of a stainlesssteel entomological pin $(38 \times 0.55 \mathrm{~mm})$ and kept at ambient temperature for pollinating the next flower. The pollinia were deposited onto the stigma of a freshly bloomed flower at ca I0:00 h. The movement of the tooth and the CLW was observed closely for at least $8 \mathrm{~h}$ and with an aid of time-lapsed photography at I 5 min interval. As an experimental control, a piece of fresh carrot, delicately cut to a similar size as a package of four pollinia, was deposited onto the stigma of another Bu. praetervisum flower. Three replications were performed.

\section{Field observations of floral parts movements}

a) Anthesis - The openings of six mature floral buds were observed from 05:00 - 09:00 h.

b) Closing of flowers - The closing of petals and sepals was observed for six flowers between I5:00 and 23:00 h.

\section{RESULTS}

\section{Movements of floral parts}

Movements of the lip, petals and medial sepal are apparent after a bud has fully bloomed. A bud would usually start to open between 05:30 and 06:00 h (dawn breaks ca 07:00 h), and would normally complete blooming by $08: 30 \mathrm{~h}$, when the petals and sepals would be fully spread out (Fig. I). We observed three important movements involving different floral parts, including the acute tooth on each column wall (Fig. 2), during cross-pollination. They are as follows:

I. Lip movement - A flower of Bu. praetervisum, like its sibling species $B u$. macranthum sensu stricto, possesses a hinged and spring-loaded lip (fresh weight 9-I2 mg) which is kept in an open position. The delicate lip has a hollow core and floats for more than a day when preserved in pure ethanol, which has a relatively low surface tension under ambient conditions (Nakahira et al. 2018). The estimated minimum force required to counter the spring-loaded hinge, to overcome the inertia to change from an open to a closed position, was estimated to be between 3.0 and $5.1 \mathrm{mg}$. This is less than the weight of a male fruit fly visitor (5.9-2I.4 mg, $\mathrm{n}=>200$, unpublished data). When a male fruit fly is attracted to the flower via a floral synonome containing RK as a major component in three floral chemotypes (Nakahira et al. 2018), it typically probes and feeds mainly on the lateral sepals, especially on slippery surfaces, which arch distally over the floral column. While on the slippery side of the lateral sepals, particularly near the arched distal section, a fly might slip whilst feeding and fall either directly onto the column or 
(A)

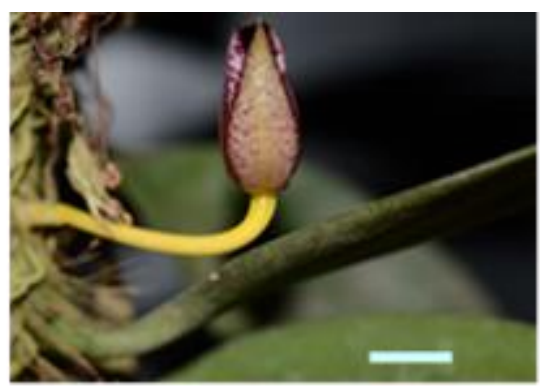

(D)

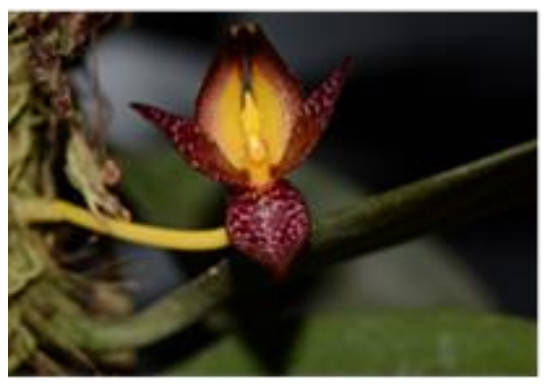

(B)

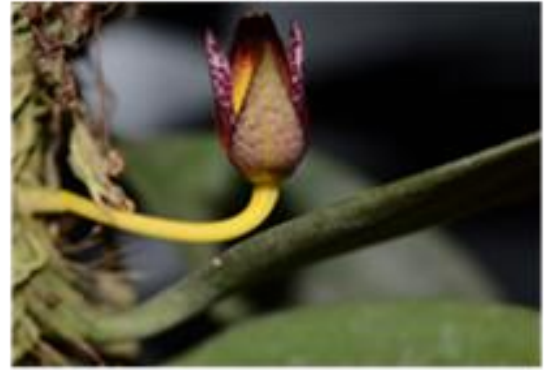

(E)

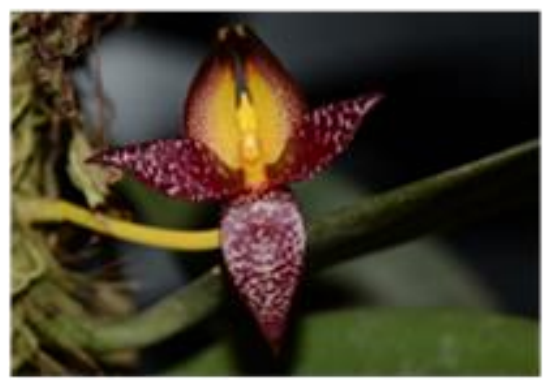

(C)

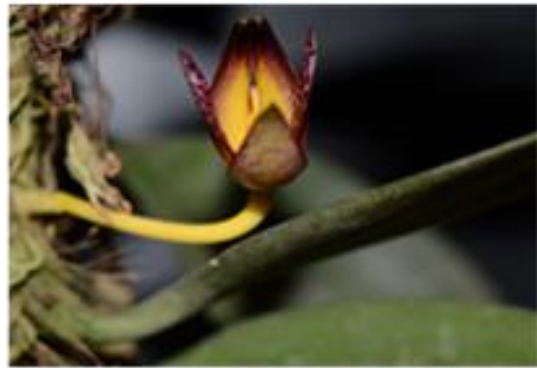

( $\mathrm{F})$

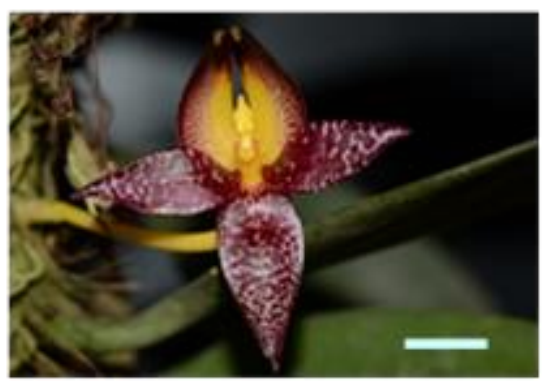

Figure I. Anthesis of Bulbophyllum praetervisum. Bar: I cm (A) Bud begun to open (at 05:50 h). (B) 40 minutes later. (C) I hour later. (D) I.5 hours later. (E) 2 hours later. (F) Fully bloom (at 08:20 h).

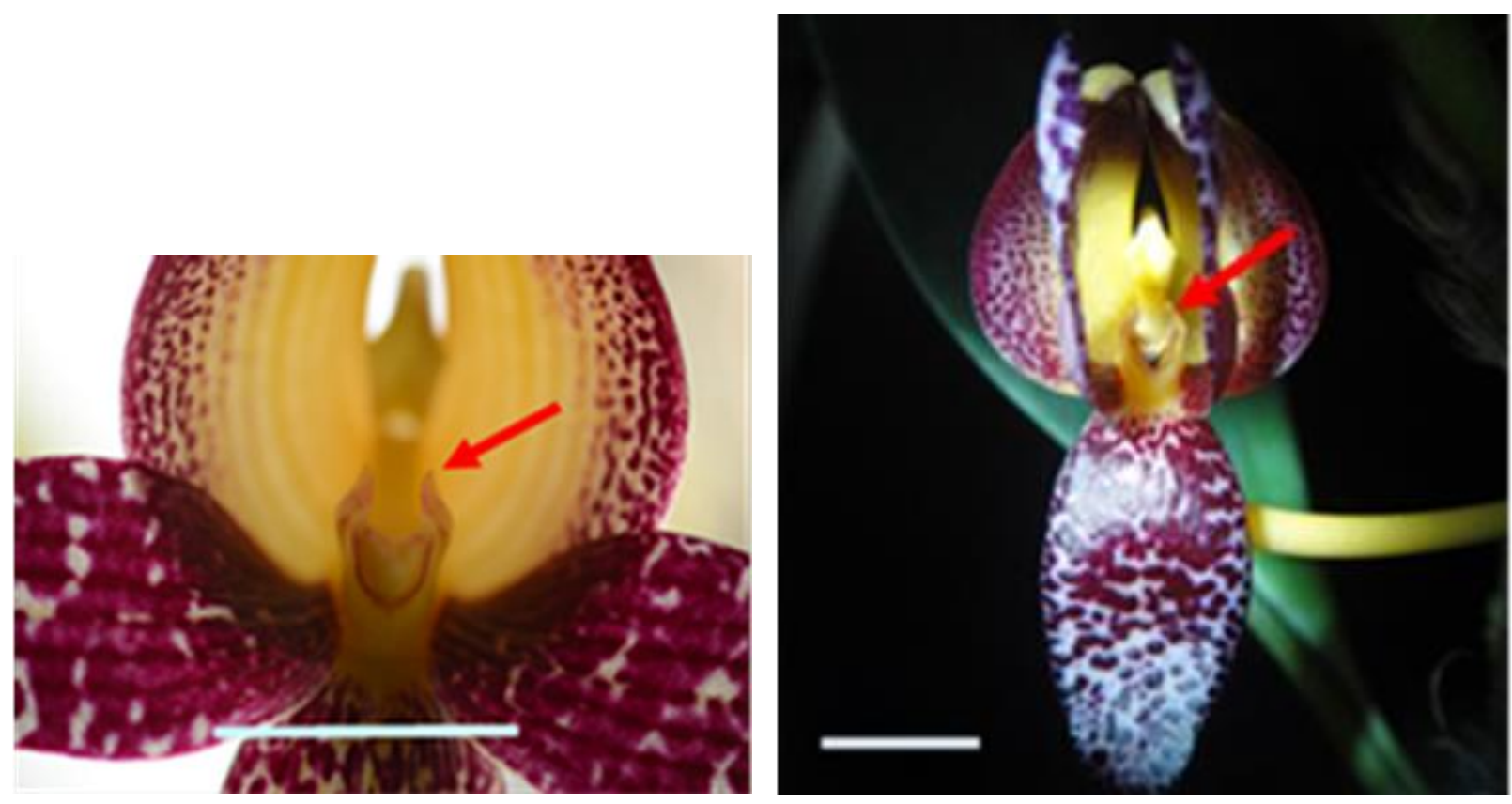

FIGURE 2. Acute tooth (arrow) on each column wall of Bulbophyllum praetervisum flower. Bar: $\mathrm{I} \mathrm{cm} \mathrm{-} \mathrm{Left:} \mathrm{Flower} \mathrm{fully} \mathrm{bloomed} \mathrm{in} \mathrm{the}$ morning. Rigth: Flower partially closed after pollinia removal - sometimes no tooth movement (at 21:00 h).

onto the lip. In the latter case, the lip immediately tips the fly backwards, abdomen first, onto the column. The fly's weight spontaneously forces the lip into a closed position. While glued to the column, the fly can repeatedly grip and release the lip, which instantly springs back to the open position when released. In the latter situation, the fly is often left to struggle vigorously - legs in the air without any support from a substratum. The movement of the lip may provide an additional outward force, allowing the fly to crawl out and free itself from being glued to the column during either removal or deposition of pollinia.

II. Movement of petals and sepals - Regardless of whether pollinia were removed or not, during late afternoon, especially when the light intensity begins to fall (at about I 5:00 h) (Fig. $3 \mathrm{~A}$ ), the flower begins to close partially for the night (requiring a period of several hours). Initially, the petals move very slowly towards each other, to the point of almost 

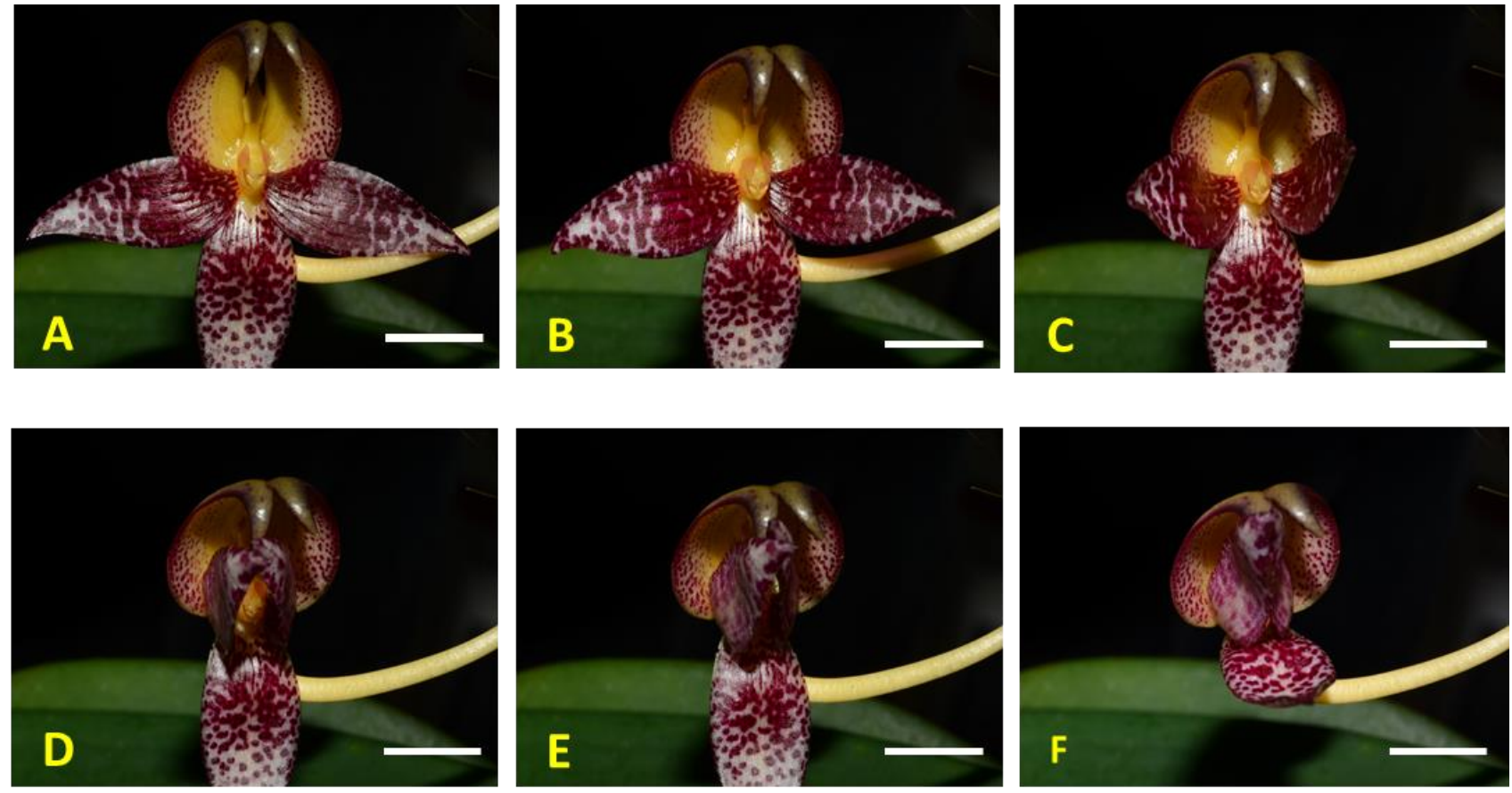

FiguRE 3. Closing of Bulbophyllum praetervisum flower for the night when not pollinated. (A) Process initiated with petal tips moving forward - at ca 15:00 h. (B) Tips of column wall teeth moved towards each other - at 18:00 h. (C) Tips of teeth overlap slightly and petal tips in front of the column - at I8:30 h. (D) Teeth overlap and petal tips touching over column and below lateral sepal tips - at 19:00 h. (E) Column hidden and medial sepal began folding - at 20:00 h. (F) Medial sepal moved to a horizontal position - at 23:00 h.

touching above the column (Fig. 3B-D), followed more than an hour later by the medial sepal also moving very slowly from a vertical to an almost horizontal position (Fig. 3E\&F). The movement of the latter may not be obvious during the late afternoon. This partial closing of petals and sepals probably serves a) to protect the floral sexual parts from unwelcome nocturnal visitors (Fig. 3E\&F), and b) to prevent floral volatiles on the petal, lateral sepal and lip surfaces from being washed away by dew or rain. It should be noted that sometimes a flower may not close on the first night after anthesis. Any reason given for this would be highly speculative, and it warrants further investigation. The movements of different floral parts of the flower during partial closing for the night were reversed the next morning. On the second day, an unpollinated flower will reopen and receive potential visitors again. Pollinia removal by males of RK-responsive species, namely, Ba. albistrigata, Z. caudatus, $Z$. cucurbitae and $Z$. tau, have been observed.

III. Movement of the tooth of the column wall - The acute tooth is slightly arched distally over the stigma cavity (Fig. 2A). It sometimes does not show any movement, even after pollinia removal, when the flower closes for the night (Fig 2B). During a normal closing for the night, after the petals started to move as described above, the folding of the teeth to the point of overlapping each other just prior to sunset (Fig. 3 B-D) may serve to prevent unwelcome nocturnal insect visitors. However, during the morning after a set of pollinia was deposited onto the stigma (Fig. 4A) (by a male fly - either Ba. albistrigata or Z. caudatus, a very rarely observed phenomenon, witnessed on only two occasions over a period of two decades), the 'tooth' began to fold inwards to face the stigma until they touched each other, and subsequently one on top of the other over the newly deposited
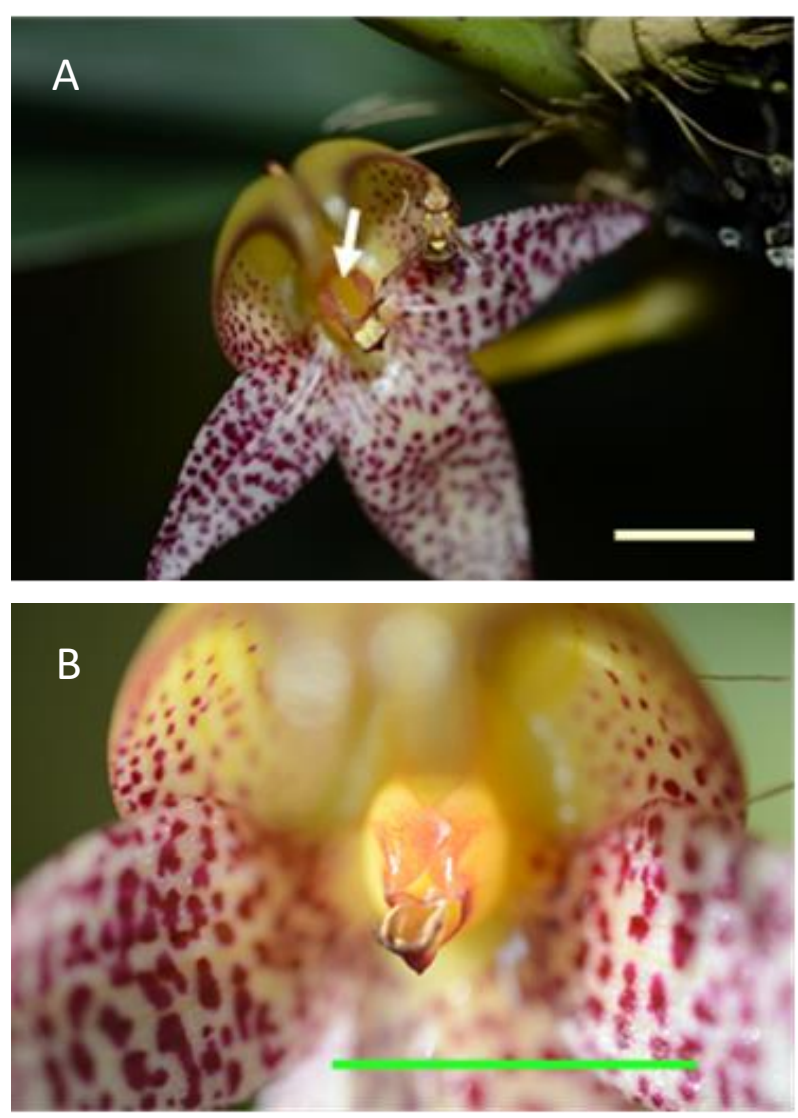

FIGURE 4. Natural pollination of Bulbophyllum praetervisum by a Dacini fruit fly. (A) Freshly deposited pollinia (arrow) on the stigma by a fruit fly. (B) Column wall teeth folded to cover the pollinia, ca $4.5 \mathrm{~h}$ after deposition by the fly. Bar: $\mathrm{I} \mathrm{cm}$ 

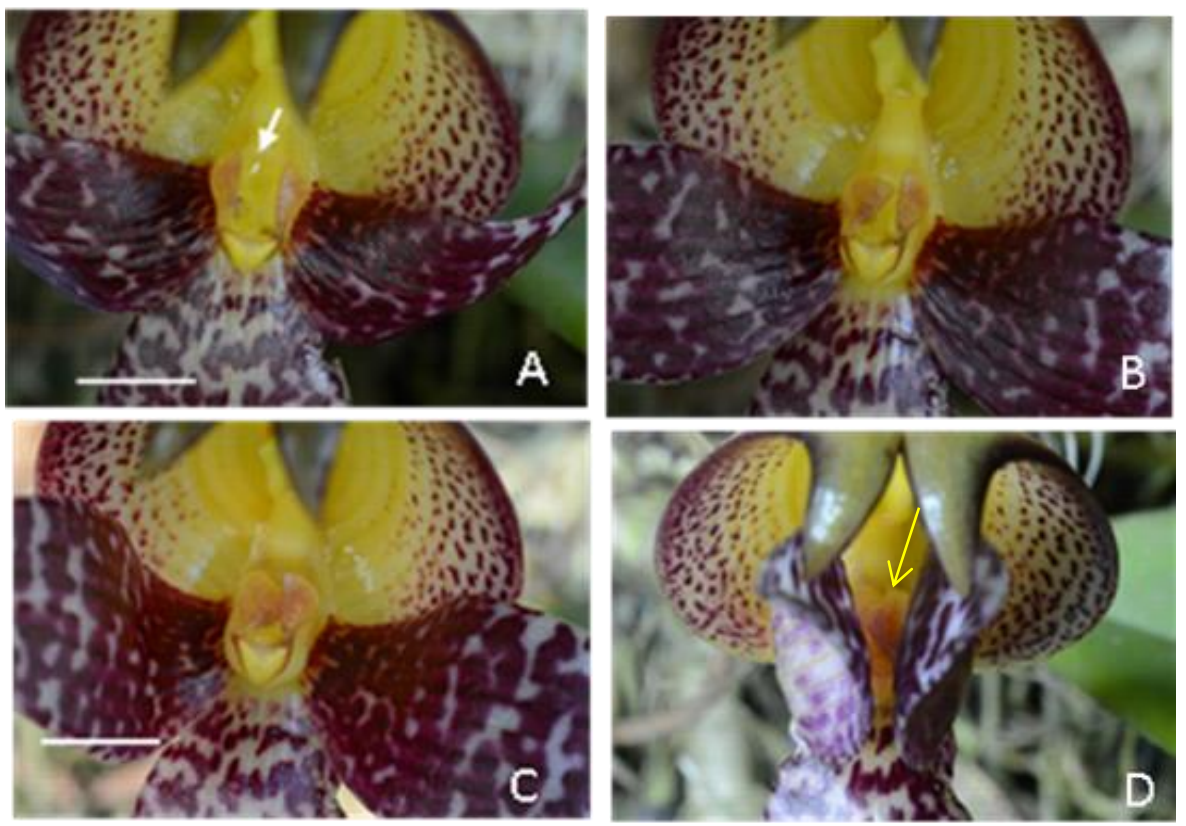

FIGURE 5. Column lateral wall (CLW) and 'tooth' movement after pollinia (arrow) were artificially deposited. Bar: $0.5 \mathrm{~cm}$ (A) Left tooth started to move inwards - after $2 \mathrm{~h}$. (B) Left CLW folded over pollinia - after $5 \mathrm{~h}$. (C) Right CLW folding over left after 7 h. (D) CLW overlapped (arrow) over the pollinia with petals almost touching - II h.

pollinia (Fig 4B) - as a mother hugs her infant close to her chest. This movement can be induced by artificially pollinating a flower with pollinia from another flower. Figure $5 \mathrm{~A}$ shows the pollinia on the stigma ca $2 \mathrm{~h}$ after deposition. The left tooth started to fold very slowly inwards first (Fig. $5 \mathrm{~B}$ ), followed by the right tooth ca $2 \mathrm{~h}$ later (Fig. 5C). The column wall movement to cover the deposited pollinia took about II $h$ to complete. The completed movement approximately coincided with the closing of the petals to the point of almost touching each other over the floral column (Fig. 5D). No tooth movement was observed in the controlled flowers when they closed and eventually dropped off. Therefore, it appears that the pollinia may contain certain surface chemical/molecular factors that induce the tooth movement when a flower is pollinated.

This is the first report of the tooth movement followed by that of the CLW (in order to protect and firmly secure the deposited pollinia to the stigma). This final of the three movements shown by floral parts thereby ensures successful cross pollination by a Dacini fruit fly, leading subsequently to fertilisation of the flower and ultimately to the production of seeds within a capsule (Fig. 6). It should be pointed out that our observations showed that Bu. praetervisum is selfincompatible, as no seed capsule was formed after selfpollination.

\section{Role of column lateral walls (CLW) during pollination}

Observations show that the CLW serve as guiding flaps to align a fly, either falling backwards (abdomen first) from the slippery lateral sepals or being tipped backwards by the closing hinged lip (due to a weight imbalance), in the correct longitudinal position against the floral column to allow either pollinia removal or deposition. When in the correct alignment, the column walls would be on each side of the fly, especially along the fly's abdomen. In this position, the fly,

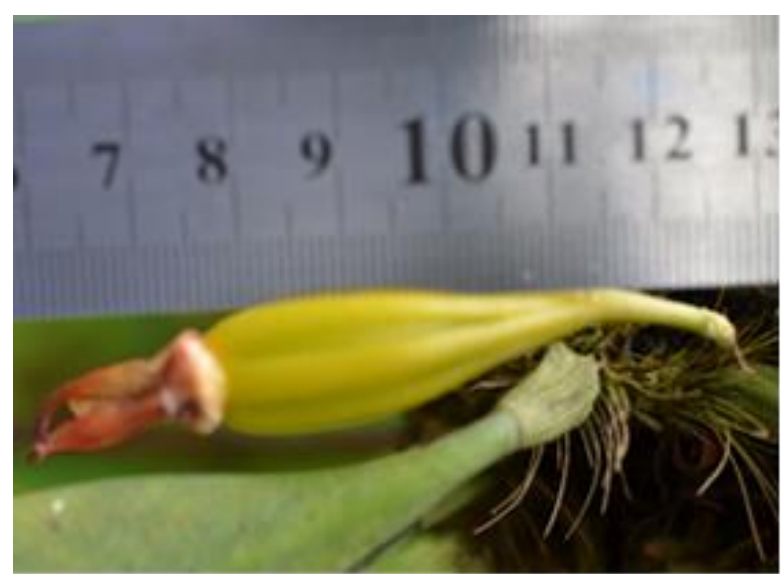

FIGURE 6. Seed capsule - 4 weeks old.

with its head and thorax above the column cavity and each wing just above the tooth, will wiggle and struggle vigorously to free itself, thereby touching the viscidium, at which point the pollinia were removed by sticking to the fly's abdomen dorsally (Fig. 7). However, if the fly bears pollinia on its abdomen, it will deposit them onto the stigma during its struggle. For the various sibling species of the Bu. macranthum complex, the pollinia, when removed, were invariably stuck to the fly's abdomen (Tan 2009; Ong et al 20I I; Tan \& Nishida 2013). This is where other daciniphilous Bulbophyllum species, namely Bu. ecornutum (previously published as $B u$. apertum), Bu. baileyi, Bu. cheiri, Bu. elevatopunctatum and Bu. vinaceum - where pollinia are invariably stuck onto the fly's thoracic dorsum - differ from the Bu. mactanthum species complex (Tan \& Nishida 2000, 2005, 2007, 2013; Tan et al. 2002, 2006; Ong et al. 201 I).

The flexible and soft tooth of the column wall may provide a certain amount of support so that a stuck fly can move from side to side to loosen the pollinia before it 


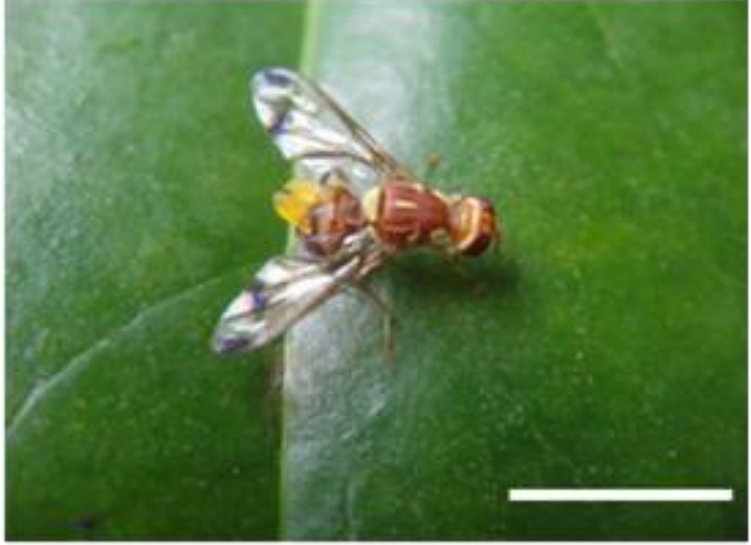

FIGURE 7. Pollinia of Bulbophyllum praetervisum on abdomen of the melon fly. Bar: $\mathrm{I} \mathrm{cm}$

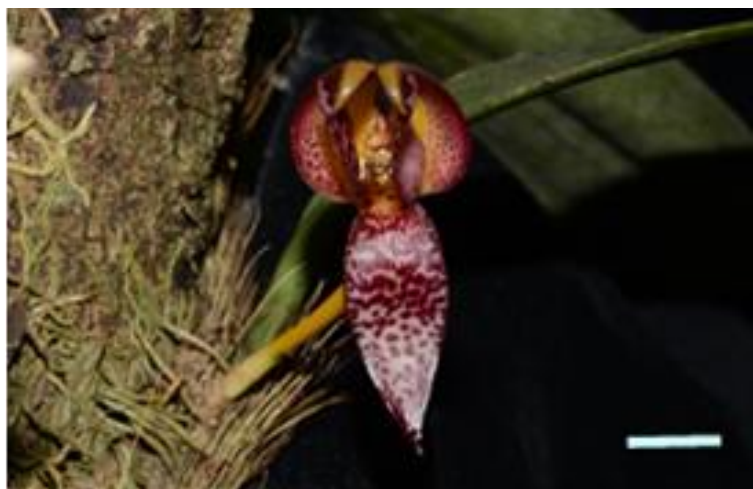

FIGURE 8. A Bulbophyllum praetervisum flower partially closed for the night. Note: a dead melon fly, Zeugodacus cucurbitae, still glued to the column. Bar: $\mathrm{I} \mathrm{cm}$

ultimately climbs out of the column cavity. When a fly is glued to the column, either while removing or depositing the pollinia, it normally spends about $0.5 \mathrm{~h}$ of intermittent struggling and resting to free itself and leave the column.

Nevertheless, sometimes either a) the tooth hindered the rapid wing movements of the fly, so that it lacked adequate lifting force to free itself; or b) the fly released the lip too early, and thereby lost the opportunity to have a substratum on which it could crawl away from the column; or a combination of both a) and b). In such situations, a fly may be glued forever and eventually die due to dehydration (witnessed on more than a dozen occasions; also reported by Ong et al. 20II) (Fig. 8). As a result, the orchid flower could neither be pollinated nor fertilised.

The second and equally important role of the tooth of the CLW is that of securing a newly deposited package of pollinia onto the stigma. Therefore, when a compatible set of pollinia has been securely deposited, cross pollination is accomplished and will yield ultimately a seed capsule.

\section{ACKNOWLEDGEMENTS}

We gratefully thank R. Nishida for his thirty years of moral support and interest on Bulbophyllum orchid chemical ecology. Our sincere appreciation also goes to J.J. Vermeulen for providing the original plants to grow ex situ.

\section{REFERENCES}

Baker HG (1963) Revolutionary mechanisms in pollination biology. Science 139: 3558.

Chan CL, Lamb A, Shim PS, Wood, JJ (1994) Orchids of Borneo. Vol. I - Introduction and a selection of species. The Sabah Society, Kota Kinabalu, Sabah, Malaysia and Bentham-Moxon Trust, England.

Christensen DE (I994) Fly pollination in the Orchidaceae., In: J. Arditti (ed) Orchid Biology, Reviews and Perspectives, VI. John Wiley \& Sons, New York, NY, pp 4I5-454.

Clinger van der NA (200I) An alas of orchid pollination. America, Africa, Asia, Australia. A.A. Balkema, Rotterdam, The Netherlands.

Flügel H-J (2013) The Sepsidae from the 'Lebendiges Bienenmuseum' (Diptera) and her flower visit in Middle Europe (in German). Phillipia 16:8I-93.

Jersakova J, Johnson SD, Kindlmann, P (2006) Mechanisms and evolution of deceptive pollination in orchids. Biol. Rev. 8I: 219235.

Kaiser R (1993) The scents of orchids, olfactory, and chemical investigations. Elsevier, The Netherlands.

Kastinger C, Weber A (200I) Bee-flies (Bombylius spp. Bombyliidae, Diptera) and the pollination of flowers. Flora Jena 196:3-25.

Larson BMH, Kevan PG, Inouye DW (200I) Flies and flowers: Taxonomic diversity of anthophiles and pollinators. Canadian Entomologist 133:439-465.

Lord E M, Russell SD (2002) The mechanisms of pollination and fertilization in plants. Annu. Rev. Cell Dev. Biol. I8: 8I-I05.

Nakahira M, Ono H, Wee SL, Tan KH, Nishida R (2018) Floral Synomone diversification of two Bulbophyllum sibling species (Orchidaceae) in attracting fruit fly pollinators (Diptera: Tephritidae). Biochemical Systematics and Ecology 8I:86-95.

Nishida R, Tan KH, Wee SL, Hee AKW, Toong YC (2004) Phenylpropanoids in the fragrance of the fruit fly orchid, Bulbophyllum cheiri, and their relationship to the pollinator, Bactrocera papayae. Biochemical Systematics and Ecology 32:245252.

Ong PT, Tan KH (20II) Fly pollination in four Malaysian species of Bulbophyllum (Section Sestochilus) - B. lasianthum, B. lobbii, $B$. subumbellatum and $B$. virescens. Malesian Orchid Journal 8:I03-IIO

Ong PT, Hee AKW, Wee SL, Tan KH (20II) The attraction of flowers of Bulbophyllum (Section Sestochilus) to Bactrocera fruit flies (Diptera: Tephritidae). Malesian Orchid Journal 8:93- I02.

Pijl van der L, Dodson CH ( 1969 ) Orchid flowers, their pollination and evolution, second edition. University of Miami Press, Florida. $2 \mathrm{I} 4 \mathrm{pp}$.

Radian FX, Padmarsari W (2012) Pollination biology of orchids of the genus Bulbophyllum in Labian-Leboyan Corridor. pp I09-II2. In: Widmann P, Tiju A, Putra MH, Syahirsyah, Wulffraat S (eds.) Connecting Diversity - People and Nature of Labian-Leboyan Corridor in the Indonesian Heart of Borneo. WWF-Indonesia. www.hobgreeneconomy.org/downloads/Connectingdiversity_peo pleandnature.pdf

Ridley HN (I890) On the method of fertilization in Bulbophyllum macranthum, and allied orchids. Annals of Botany 4:327-336.

Schiestl FP, Peakall R, Mant JM, Ibarra F, Schulz C, Franke S, Francke W (2003) The chemistry of sexual deception in an orchidwasp pollination system. Science 302:437-438. 
Tan KH (2009) Fruit fly pests as pollinators of wild orchids. Orchid Digest, 73:180-I87.

Tan KH, Nishida R (2000) Mutual reproductive benefits between a wild orchid, Bulbophyllum patens, and Bactrocera fruit flies via a floral synomone. Journal of Chemical Ecology 26:533-546.

Tan KH, Nishida R (2005) Synomone or Kairomone? Bulbophyllum apertum (Orchidaceae) flower releases raspberry ketone to attract Bactrocera fruit flies. Journal of Chemical Ecology 3I(3):509-5I9.

Tan KH, Nishida R (2007) Zingerone in the floral synomone of Bulbophyllum baileyi (Orchidaceae) attracts Bactrocera fruit flies during pollination. Biochemical Systematics and Ecology 35:334$34 \mathrm{I}$.

Tan KH, Nishida R (2012) Methyl eugenol - its occurrence, distribution, and role in nature, especially in relation to insect behavior and pollination. Journal of Insect Science I2:56 I-74. online: insectscience.org/I2.56

Tan KH, Nishida R (2013) Pollination of bactrocerophilous Bulbophyllum Orchids. In: Elliott J, Kurzweil HF, O'Byrne P, Tan
KW, van der Schans AS, Wong SM, Yam TM (eds.) Proceedings of the 20th World Orchid Conference, Singapore Botanic Gardens, Singapore, pp 273-279.

Tan KH, Nishida R, Toong YC (2002) Floral synomone of a wild orchid, Bulbophyllum cheiri, lures Bactrocera fruit flies for pollination. Journal of Chemical Ecology 28:I I6I-II72.

Tan KH, Tan LT, Nishida R (2006) Floral phenylpropanoid cocktail and architecture of Bulbophyllum vinaceum orchid in attracting fruit flies for pollination. Journal of Chemical Ecology 32:2429-244I.

Vermeulen JJ (199I) Orchids of Borneo. vol. 2 - Bulbophyllum. Bentham-Moxon Trust, Toihaan Publishing Co. and the Sabah Society, Kota Kinabalu, Sabah, Malaysia 342 pp.

Vermeulen JJ (2002) Bulbophyllum praetervisum J.J. Verm. (Orchidaceae), an overlooked species close to B. macranthum Lindl. Gardens' Bulletin. Singapore 54:153-I54.

Woodcock TS, Larson BMH, Kevan PG, Inouye DW, Lunau K (20I4) Flies and flowers II: Floral attractants and rewards. Journal of Pollination Biology I2:63-94. 